\title{
A TRAMITACIÓN AMBIENTAL DE NOVOS ESTABLECEMENTOS NA COMUNIDADE AUTÓNOMA GALEGA DESPOIS DA LEI 9/2013 DO EMPRENDEMENTO E DA LEI 21/ 2013 DE AVALIACIÓN AMBIENTAL
}

Fernando BLANCO SILVA, Dr. enxeñeiro industrial do Corpo superior de enxeñeiros industriais da Xunta de Galicia. Fernando.blanco.silva@xunta.es. Delegación de Santiago de Compostela do Colexio Oficial de Enxeñeiros Industriais de Galicia Alfonso LÓPEZ DÍAZ, Dr. profesor da Universidade Católica de Ávila. Facultade de Ciencias e Artes, Ávila (España)lffonso.lopez@ucavila.es.

\section{RESUMO}

No ano 2013 aprobáronse a Lei 21/2013, do 9 de decembro, de avaliación ambiental e a Lei 9/2013, do 19 de decembro, do emprendemento e da competitividade económica de Galicia, que supoñen un cambio na normativa para a formulación de novos establecementos nesta Comunidade, en función do impacto ambiental que provocarán; a estes dous documentos normativos debénselle engadir a necesidade do cumprimento da Lei 16/2002, do 1 de xullo, de prevención e control integrados da contaminación para actividades que emitan elevadas cantidades de gases contaminantes. Neste artigo realizamos unha análise das tres leis, así como unha explicación de como resulta o procedemento de autorización de novos establecementos na actualidade na Comunidade Autónoma de Galicia.

Palabras chave: Establecemento, licenza de actividade, Declaración de Incidencia Ambiental, Declaración de Impacto Ambiental, comunicación previa.

\section{INTRODUCIÓN}

A Constitución Española no seu Artigo 45 recolle "o dereito a desfrutar dun medio ambiente axeitado para o desenvolvemento da persoa, así como o deber de conservalo", e o deber dos poderes públicos de "protexer e mellorar a calidade da vida e defender e restituír o medio ambiente (...)"; ademais o Artigo 149.1.23 recolle que o Estado ten competencia exclusiva sobre a lexislación básica de protección ambiental, sen prexuízo das facultades das Comunidades Autónomas de establecer normas adicionais [1]; nesta liña o Estatuto de Autonomía de Galicia recolle no seu Artigo 27 a competencia exclusiva da Comunidade Autónoma en "Normas adicionais sobre protección do medio ambiente e da paisaxe nos termos do Artigo 149.1.23". [2]. A este complexo repartimento de competencias debémoslle engadir as municipais, que se regulan fundamentalmente nos Artigos 7 e 25 da Lei 7/ 1985, do 2 de abril, reguladora das Bases do Réxime Local [3], e basicamente son a elaboración de normativa propia adicional (de forma opcional) e as licenzas de actividade, coas particularidades que aquí exporemos.

\section{A INTRODUCIÓN DA NORMATIVA AMBIENTAL EN ESPAÑA}

A norma histórica de referencia con respecto ao medio ambiente é o Regulamento de Actividades Molestas, Insalubres, Nocivas e Perigosas (R.A.M.I.N.P.) de 1961, que recolle as limitacións para evitar as molestias que causaban as actividades industriais (chamadas actividades clasificadas). Este documento é un excelente marco xurídico que se mantén en vigor ata 2007 [4]. O Artigo 6 do R.A.M.I.N.P. recolle que "será competencia dos Alcaldes a concesión de licenzas para o exercicio das actividades reguladas, a vixilancia para o mellor cumprimento destas disposicións e o exercicio da facultade sancionadora (...)"; é dicir que antes da abertura de calquera actividade clasificada era necesario solicitar autorización ao municipio. Incluíase como "actividades clasificadas" un amplo ANEXO I. Nomenclátor anexo á Regulamentación de actividades molestas, insalubres, nocivas e perigosas do mesmo R.A.M.I.N.P., aínda que este Nomenclátor non ten carácter limitativo, senón que outras actividades de impacto semellante tamén deben ser sometidas a esta licenza e por 
extensión calquera actividade que puidera ter algún compoñente contaminante esixía autorización previa.

Incluímos a continuación a descrición que fai López Ramón do proceso de licenza municipal [5]: As actividades clasificadas requiren precisamente da licenza municipal outorgada conforme ao procedemento especial do R.A.M.I.N.P. A solicitude de licenza debe ir acompañada dun proxecto técnico e memoria descritiva das características da actividade, a súa repercusión sobre a sanidade ambiental e os sistemas correctores previstos (art. 29). 0 alcalde pode denegar directamente a licenza "por razóns de competencia municipal" (art. 30.1); noutro caso, a solicitude someterase a información pública, audiencia de interesados ("os veciños inmediatos ao lugar de situación proposto") e informes de diversos dos funcionarios locais (art. 30.2), incorporándose un informe final da corporación municipal (art.30.3).

O proceso de Avaliación de Impacto Ambiental iníciase nos anos setenta, a partir da Lei Nacional de Política Ambiental aprobada nos EEUU e a Conferencia de Medio ambiente de Estocolmo [6]; durante os anos setenta e oitenta, os países desenvolvidos elaboraron programas e normativas cuxo fin era preservar o medio ambiente "dende un enfoque sectorial, cuxo fin era eliminar ou, alomenos, diminuír o problema da contaminación a través do seguemento dunhas normas mínimas en materia de residuos, auga e ar" [7]; no caso particular dos Estados Membro "as primeiras directrices de loita contra a contaminación das décadas dos setenta e oitenta tiñan un enfoque sectorial e, como consecuencia, unha visión parcial e compartimentada das problemáticas ambientais" segundo Juan José Pernas García [8].

España actuou nesta liña e de forma sectorial aproba a normativa ambiental limitando os efectos sobre o medio natural de certas actividades; un claro exemplo desta liña é a Lei 82/1980, do 30 de decembro, sobre conservación de enerxía [9]; é una Lei sectorial, orientada á redución do consumo de hidrocarburos e fomento das enerxías renovables pero no seu contido non recolle explicitamente o concepto de "medio ambiente" ou "contaminación"; outros exemplos son as de ordenación urbanística. Coa entrada de España na UE aplícanse as directivas comunitarias (en particular a Directiva 85/377/ CEE do 27 de xuño de 1985, relativa á avaliación das repercusións de determinados proxectos públicos e privados sobre o medio ambiente [10]) e introdúcese por primeira vez esta avaliación. A Directiva fai referencia á "avaliación das repercusións", que, segundo Rosa Montero (2004), na práctica é a avaliación de impacto ambiental [11].

A Directiva 85/ 377/ CEE trasponse a España no Real Decreto Lexislativo 1302/ 1986, do 28 de xuño, de Avaliación de Impacto Ambiental [12], como primeiro documento xurídico que se vencella explicitamente ao impacto ambiental. Este Real Decreto Lexislativo por primeira vez obriga a que se sometan os grandes proxectos á Avaliación de Impacto Ambiental (E.I.A.) como procedemento xenérico, no que un técnico competente debe redactar un documento técnico para minimizar os efectos do proxecto.

Unha vez analizada a situación previa en España entraremos a analizar a normativa autonómica: o Decreto 442/ 1990, do 13 setembro de Avaliación de impacto ambiental [13] e a Lei 1/ 1995 de protección ambiental da Comunidade Autónoma [14].

Xa citamos o Real Decreto Lexislativo 1302/ 1986, do 28 de xuño, de Avaliación de Impacto Ambiental de aplicación estatal; en aplicación da competencia autonómica de aprobar normativa engadida, apróbase o Decreto 442/1990, do 13 de setembro de Avaliación de impacto ambiental para Galicia como unha extensión do Real Decreto Lexislativo. O Decreto 442/ 1998 de Avaliación de Impacto ambiental foi derrogado pola Lei 9/2013, do 19 de decembro, do emprendemento e da competitividade económica de Galicia. 


\section{A LEI 1/1995, DO 2 DE XANEIRO, DE PROTECCIÓN AMBIENTAL DA COMUNIDADE AUTÓNOMA DE GALICIA}

En 1995 non existía unha Lei Básica de Medio Ambiente Estatal, polo que algunhas Comunidades aproban as súas propias leis de algo que a nivel estatal non estaba regulado; "esta mesma opción - de aprobación de leis xerais sobre o medio ambienteseguírona, ata o momento, outras Comunidades Autónomas como Madrid, Andalucía, Murcia, e País Vasco [15]". Esta Lei 1/1995 ten un carácter xeral para a Comunidade Autónoma e non regula unicamente as actividades en función do seu impacto ambiental senón que tamén vai incentivar a concienciación e educación ambiental da poboación galega, procura institucionalizar os contactos entre a administración ambiental e a Comunidade científica, espertar unha conciencia ecolóxica entre os cidadáns e finalmente incluír un procedemento regulatorio do incumprimento desta Lei (réxime de inspeccións); no seu contido introduce a procura dun pacto ambiental en situacións conflitivas, procurando un acordo entre as entidades contaminantes e o resto de interlocutores; este pacto é recoñecido como "innovador e moi positivo" segundo Severino González Álvarez [16]. A día de hoxe, a Lei 1/1995 está parcialmente en vigor, aínda principalmente vencellada ás actividades de concienciación ambiental, porque o réxime de actividade está regulado pola Lei 9/2013, do 19 de decembro, do emprendemento e da competitividade económica de Galicia que se comentará posteriormente.

\section{LEI 16/ 2002, DO 1 DE XULLO, DE PREVENCIÓN E CONTROL INTEGRADOS DA CONTAMINACIÓN}

Unha vez marcados os criterios básicos da avaliación ambiental, comézase a reforzar a vixilancia ambiental sobre as tarefas máis contaminantes; o primeiro documento normativo a nivel estatal que concreta a vixilancia ambiental é a Lei 16/2002, do 1 de xullo, de Prevención e Control Integrados da Contaminación [17]. Esta Lei 16/2002 é a trasposición da Directiva 96/ 61 de prevención e control integral da contaminación (tamén denominada Directiva IPCC) que procura garantir a calidade do ar; para isto céntrase nas actividades que xeran emisións en grandes cantidades (combustión, incineración de residuos,.....). Nestes casos o procedemento administrativo que permite a actividade é a Autorización Ambiental Integrada, que será outorgada polos organismos competentes das Comunidades Autónomas, despois un procedemento de información pública e comprobación da compatibilidade da explotación coa ordenación urbanística (e o resto da normativa municipal). Para ser outorgada a Autorización Ambiental Integrada é necesario aplicar as Mellores Técnicas Dispoñibles (MTDs) e garantizarase que as emisións por actividade non superen os niveis de emisión asociados a estas M.T.D.s; o uso destas M.T.D.s supón un custo moi elevado para o promotor, e só se poderán deixar de aplicar cando a súa aplicación supoña uns custos desproporcionados. As actuacións serán revisadas e actualizadas con periodicidade de catro anos [18]. O Anexo 1 inclúe as instalacións afectadas, tales como instalacións de combustión, refinarías de petróleo, produción e transformación de metais, industrias minerais, químicas, xestión de residuos, industria derivada da madeira, industria téxtil, coiro, alimentarias e ganderias; na maioría dos casos cuns límites de produción que o lexislador considera suficientemente contaminantes.

\section{A LEI DE IMPACTO AMBIENTAL DE PROXECTOS, TEXTO REFUNDIDO APROBADO POLO REAL DECRETO LEXISLATIVO 1/ 2008, DO 11 DE XANEIRO E A LEI 9/2006, DO 28 DE ABRIL, SOBRE AVALIACIÓN DOS EFECTOS DE DETERMINADOS PLANS E PROGRAMAS NO MEDIO AMBIENTE}

Durante os seguintes anos apróbanse basicamente dous documentos normativos de relevancia como son a Lei de Impacto Ambiental de proxectos, texto refundido aprobado 
polo Real Decreto Lexislativo 1/2008, do 11 de xaneiro [19] e a Lei 9/2006, do 28 de abril, sobre avaliación dos efectos de determinados plans e programas no medio ambiente [20]. Estas dúas normas teñen unha estrutura semellante, porén ámbitos de aplicación diferentes; o primeiro para proxectos namentres que o segundo é para plans e programas (de contido máis difuso). Cada un deles recolle procedementos semellantes; trátanse de actividades con menor impacto cas reguladas pola Lei 16/2002, sendo o órgano competente a Comunidade Autónoma.

As instalacións afectadas polo Real Decreto Lexislativo 1/2008 e pola Lei 9/ 2006 son en xeral as que recollía o Real Decreto Lexislativo de 1986; trátase de actuacións de elevado impacto.

\section{A LEI 17/2009, DO 23 DE NOVEMBRO, SOBRE $O$ LIBRE ACCESO ÁS ACTIVIDADES DE SERVIZOS E 0 SEU EXERCICIO}

Unha vez "derrogado" o Regulamento de Actividades Molestas Insalubres Nocivas e Perigosas complícase aínda máis a licenza de actividade coa aprobación da Lei 17/ 2009 sobre o libre acceso ás actividades de servizos e o seu exercicio. 0 mesmo R.A.M.I.N.P. obrigaba a que o municipio concedera unha licenza de actividade a infinidade das actividades empresariais, xa que son moitas as recollidas no Nomenclátor, ou aquelas que non estando incluídas se asimilan ás mesmas, e que o municipio decide esixir a devandita licenza.

A Lei 17/ 2009 ten como fin fomentar a liberalización dos servizos e establecementos como trasposición da Directiva 2006/123/ CE do Parlamento Europeo e do Consello, do 12 de decembro de 2006, relativa aos servizos no mercado interior. Esta Directiva procura diminuír a intervención administrativa no máximo número de actividades e reducir os atrancos inxustificados para o exercicio das actividades de servizos, proporcionando unha contorna máis transparente para a creación de empresas, porén aínda existen restricións sectoriais en sectores máis "delicados" (correos, enerxía, servizos financeiros, telecomunicacións, transportes, ETTs, sanitarios...). Ademais simplifica os procedementos.

A aprobación da Lei 17/ 2009 supón unha modificación moi importante na normativa española de cara aos novos establecementos, xa que só de forma moi xustificada poderíase "entorpecer" a implantación de novos establecementos cunha licenza administrativa a cargo do propio concello. Destacamos a análise de JR Chaves na web www.contencioso.es [21], "A vixencia das leis encamiñadas a poñer en práctica a liberalización dos servizos e establecementos propiciada pola Unión Europea e que afecta ao réxime de licenzas no ámbito local, tras a modificación provocada pola Lei 17/ 2009 na Lei de Bases de Réxime Local (en cumprimento da Directiva de Servizos 2006/123/ CE), deixa no limbo a situación das licenzas esixidas para a instalación e/ ou abertura de actividades contempladas no anexo do Regulamento de Actividades Molestas, Nocivas, Perigosas e Insalubres de 1961.

(...) É certo que algunhas actividades, tales como a sanitaria, audiovisual ou de seguridade privada, están expresamente excluídas do ámbito da directiva, pero as restantes quedaron excluídas da exigencia de autorización ou licenza previa tal e como deriva da normativa comunitaria.

Ou sexa, que a tempo real, os Concellos atoparanse con que boa parte das actividades clasificadas non se poden suxeitar a previa licenza nin moito menos aos molestos trámites do RAMI. Así de crudo e así de claro".

Isto supuxo a necesidade de que os concellos modificaran os seus procedementos, evitando os tediosos trámites de obtención de licenzas, xa que en aplicación desta Lei $17 / 2009$, eran dificilmente xustificables na meirande parte das actividades denominadas "reguladas". 


\section{LEI 21/ 2013, DO 9 DE DECEMBRO, DE AVALIACIÓN AMBIENTAL}

Esta Lei foi aprobada en decembro de 2013, e derroga a Lei 9/2006 e o Real Decreto Lexislativo 1/2008; aínda que introduce alguhnas variacións a grandes trazos o que fai é unificar os seus criterios.

No seu preámbulo, fai referencia a que a avaliación ambiental é un instrumento indispensable para a protección do medio ambiente, a avaliación ambiental é un instrumento plenamente consolidado no ámbito internacional en particular no Convenio de Espoo de Avaliación de Impacto Ambiental de 1991; no ámbito comunitario destacamos a Directiva 2001/42/CE de avaliación ambiental de plans e programas e a Directiva 2011/ 92/ UE de avaliación das repercusións de proxectos públicos e privados.

Esta Lei 21/2013 de Avaliación Ambiental caracterízase por uniformizar os criterios a cumprir ao instituír procedementos administrativos que autorizan planes, programas e proxectos usando os mesmos criterios. A avaliación de plans e programas por unha banda e a de proxectos eran dous procedementos distintos aínda que con moitos conceptos comúns pero que se homoxeneizan coa nova Lei 21/ 2013 e os procesos son practicamente idénticos; ademais se distingue a terminoloxía para cada caso, xa que na avaliación de plans e programas se realiza a Avaliación Ambiental Estratéxica namentres que no caso dos proxectos é a Avaliación de Impacto Ambiental.

Coa aprobación de esta Lei 21/2013 aumenta a seguridade xurídica do promotor porque se desenvolve unha lexislación homoxénea en todo o Estado Español que permita aos promotores coñecer de antemán as esixencias legais de carácter ambiental que requerirán as súas actuacións, independentemente do lugar onde se desenvolve, e se unifican as esixencias por parte das administracións autonómicas (ata este momento os criterios autonómicos non se concretaran de forma suficiente), evitando posibles deslocalizacións). O informe Desenvolvemento autonómico, competitividade e cohesión social. Medio Ambiente do Consello Económico e Social determinaba que en 2012 os requisitos para a implantación de actividades diferían moito en función da Comunidade Autónoma e ata detectou que para algunhas actividades non era necesaria autorización e noutras si. Á hora de tramitar as autorizacións debemos distinguir entre o órgano substantivo (a quen se lle solicita que a conceda) do órgano ambiental (que emitirá un informe vinculante).

Existen dous procedementos; por unha banda a avaliación de plans e programas e por outra a de proxectos; nos dous casos existen a avaliación ordinaria e a simplificada cando se trata dun ámbito más reducido.

Nos dous casos o procedemento inclúe a presentación por parte do promotor dun documento redactado por un técnico competente cos impactos que vai provocar, medidas para o minimizar, plans de vixilancia..., que será estudado pola administración, sometido como norma xeral a consultas públicas e ás persoas afectadas/interesadas (nos procedementos simplificados pode non se realizar a fase de consultas públicas), análise polas administracións públicas da documentación xerada e finalmente a emisión dun documento por parte da administración competente (en Galicia a Consellería de Medio Ambiente) coas limitacións que considera. Este documento vai recibir o nome de Declaración Ambiental Estratéxica (para plans e programas) ou Declaración de Impacto Ambiental (para proxectos); estes dous documentos teñen unha versión máis reducida cando se aplican os procedementos simplificados que se denomina Informe Ambiental Estratéxico e Informe de Impacto Ambiental. A Declaración Ambiental Estratéxica ou a Declaración de Impacto Ambiental publicarase no correspondente Diario Oficial autonómico e ten unha validez a partir desta publicación. Vemos a continuación unha táboa resumo cos procedementos ao completo: 
Táboa 1: Resumo comparativo dos dous procedementos ambiental:

\begin{tabular}{|c|c|c|}
\hline & $\begin{array}{l}\text { Avaliación Ambiental } \\
\text { Estratéxica }\end{array}$ & $\begin{array}{l}\text { Avaliación de Impacto } \\
\text { Ambiental }\end{array}$ \\
\hline Orientado a & $\begin{array}{l}\text { Plans e en menor } \\
\text { medida a proxectos }\end{array}$ & Proxectos \\
\hline $\begin{array}{l}\text { Documento presentado inicialmente } \\
\text { polo promotor }\end{array}$ & $\begin{array}{l}\text { Documento Inicial } \\
\text { Estatéxico }\end{array}$ & \\
\hline $\begin{array}{l}\text { Documento elaborado polo órgano } \\
\text { ambiental }\end{array}$ & Documento de Alcance & $\begin{array}{l}\text { Documento de alcance } \\
\text { (aínda que a súa } \\
\text { solicitude é voluntaria) }\end{array}$ \\
\hline $\begin{array}{l}\text { Documento elaborado polo promotor } \\
\text { para a avaliación ordinaria }\end{array}$ & $\begin{array}{l}\text { Estudo Ambiental } \\
\text { Estratéxico }\end{array}$ & $\begin{array}{l}\text { Estudo de Impacto } \\
\text { Ambiental }\end{array}$ \\
\hline $\begin{array}{l}\text { Dictame vinculante do órgano } \\
\text { ambiental (procedemento ordinario) }\end{array}$ & $\begin{array}{l}\text { Declaración Ambiental } \\
\text { Estratéxica }\end{array}$ & $\begin{array}{l}\text { Declaración de Impacto } \\
\text { Ambiental }\end{array}$ \\
\hline Vixencia do dictame vinculante & $\begin{array}{l}\text { Dous anos ampliables } \\
\text { con prórroga }\end{array}$ & $\begin{array}{l}\text { Catro anos ampliables } \\
\text { con prórroga }\end{array}$ \\
\hline Prórroga do dictame vinculante & Dous anos & Dous anos \\
\hline $\begin{array}{l}\text { Documento do promotor para a } \\
\text { avaliación simplificada }\end{array}$ & $\begin{array}{l}\text { Documento Ambiental } \\
\text { Estratéxico }\end{array}$ & $\begin{array}{l}\text { Documento ambiental } \\
\text { con definición básica }\end{array}$ \\
\hline Prazo para a avaliación ordinaria & $\begin{array}{l}22 \text { meses prorrogables } \\
\text { a outros dous (total } 24 \\
\text { meses) }\end{array}$ & $\begin{array}{l}\text { Catro meses } \\
\text { prorrogables por outros } \\
\text { dous a maiores (total } \\
\text { seis) }\end{array}$ \\
\hline 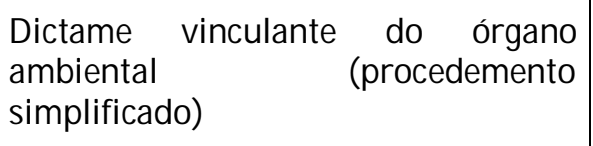 & $\begin{array}{l}\text { Informe } \\
\text { Estratéxico }\end{array}$ & $\begin{array}{l}\text { Informe de Impacto } \\
\text { Ambiental }\end{array}$ \\
\hline $\begin{array}{l}\text { Vixencia do dictame en procedemento } \\
\text { simplificado }\end{array}$ & $\begin{array}{l}\text { Catro anos, } \\
\text { renovable }\end{array}$ & $\begin{array}{l}\text { Catro anos, } \\
\text { renovable }\end{array}$ \\
\hline Prazo para a avaliación simplificada & Catro meses & Tres meses \\
\hline
\end{tabular}

O Título III recolle o réxime sancionador, no caso de incumprimento da Lei 21/2013, sendo o órgano substantivo competente o que debe seguir o cumprimento da normativa, malia que será auxiliado polo órgano ambiental.

As sancións imponranse segundo o grao de culpabilidade, reiteración, participación e beneficios obtidos, danos ao medio ambiente... sendo a potestade sancionadora do órgano substantivo clasificando entre infraccións moi graves, graves e leves, coas características seguintes: 
Táboa 2: Resumo do réxime sancionador

\begin{tabular}{|l|l|l|l|}
\hline & Sanción económica & $\begin{array}{l}\text { Prescrición } \\
\text { infracción }\end{array}$ & da \\
\hline Moi graves & $240.000 €$ a $2.4 \mathrm{M}$ & Tres anos & Tres anos \\
\hline Graves & $24.000 €$ a $240.000 €$ & Dous anos & Dous anos \\
\hline Leves & Ata $24.000 €$ & Un anos & Un anos \\
\hline
\end{tabular}

Ademais de derrogar os documentos citados (Lei 9/2006, Real Decreto Lexislativo 1/ 2008) esta Lei obriga á derrogación das normas autonómicas que non sigan a filosofía desta Lei de unificación de criterios no prazo dun ano; porén, se antes deste ano as Comunidades Autónomas aproban novos textos normativos adaptados a esta lei, a derrogación prevista no apartado anterior producirase no momento en que as novas normas autonómicas entren en vigor.

Anexo I: Proxectos sometidos a avaliación ambiental ordinaria e Anexo II: Proxectos sometidos á avaliación ambiental simplificada

Identificanse dez grupos para cada un dos dous anexos. É importante dicir que nalgúns casos as actividades xa estaban no ámbito de aplicación da Lei 16/ 2002 por producir altas emisións de gases contaminantes, dase esta situación nas centrais térmicas que teñan potencia superior a 300 MW, instalacións de refinaría de petróleo ou de produción de materiais ferrosos cunha capacidade de produción superior a 20 toneladas diarias; neste caso a Declaración de Impacto Ambiental formará parte da Autorización Ambiental Integrada como un criterio máis a cumprir pola mesma.

\section{LEI 9/2013, DO 19 DE DECEMBRO, DO EMPRENDEMENTO E DA COMPETITIVIDADE ECONÓMICA DE GALICIA. CAPÍTULO II. AVALIACIÓN AMBIENTAL DE ACTIVIDADES DO TÍTULO III. REGULACIÓN INTEGRADA DO EXERCICIO DE ACTIVIDADES}

Esta Lei 9/ 2013 de Emprendemento [22] apróbase por parte da Comunidade Autónoma para axilizar os trámites para a implantación de novas actividades económicas na mesma, en particular aplicando o procedemento de simplificación administrativa, e como norma xeral, suprímese a necesidade de licenzas ou autorización municipal previa (tal e como marcaba a Lei 17/2009) de forma que na maioría das actividades será suficiente coa presentación da comunicación previa para iniciar a actividade e só nos casos nos que a normativa o esixa, é necesaria unha autorización explícita emitida pola administración competente.

Tal e como citamos antes contarán con Autorización Ambiental Integrada todas as instalacións con altas emisións (Lei 16/2002), a continuación irían as actividades cun alto impacto ambiental, que estarán reguladas pola Lei 21/2013 de Avaliación Ambiental e, finalmente, aplícase o proceso de Declaración de Incidencia Ambiental (o menos estrito, de competencia autonómica) cando non sexa de aplicación a normativa citada; o Anexo I desta Lei 9/ 2013 do emprendemento inclúe a relación de tarefas que deben ser sometidas ao procedemento autonómico de Avaliación de Incidencia Ambiental, que citaremos a continuación.

O contido ambiental está recollido no Capítulo II. Avaliación ambiental de actividades do Título III. Regulación integrada do exercicio de actividades, e recolle a necesidade de que as actividades incluídas dispoñan da Declaración de Incidencia Ambiental para a 
implantación dunha nova actividade, antes de que sexa emitida a comunicación previa, cando non existe outra normativa específica de aplicación e non estean recollidas dentro das dúas leis antes citadas.

Nos casos incluídos no Anexo I débese contar coa Declaración de Incidencia Ambiental, que se debe incorporar á solicitude (Comunicación previa) ou alomenos dicir que se dispón dela (declaración responsable); en caso de non dispoñer dela considerarase que a declaración responsable ou comunicación previa carece de validez.

O procedemento iníciase por parte do promotor, solicitándolle á Consellería de Medio ambiente que emita a Declaración de Incidencia Ambiental para unha actividade incluída na listaxe; para isto o promotor presentará o proxecto técnico redactado por un técnico competente, e unha Memoria Ambiental. Unha vez que se solicita a Declaración de Incidencia Ambiental, o órgano ambiental publicará a memoria na súa web e asemade consultará ás outras administracións afectadas, así como a outras persoas físicas ou xurídicas que poidan ser partes interesadas. Cando o concello emita un informe de non compatibilidade do procedemento coa ordenación urbanística, este será vinculante e a resolución finalizará o procedemento, declarando a súa inadmisión ( o concello ten dereito de veto se a actuación non é apta para a ordenación urbanística vixente).

Recollidos os informes do punto anterior, o órgano ambiental vainos estudar e emitirá a Declaración de Incidencia Ambiental, coas medidas preventivas, correctoras e de restauración que correspondan á actividade. O órgano ambiental (a Consellería de Medio ambiente) terá un prazo de resolución da solicitude de dous meses dende a presentación da solicitude. A resolución finaliza coa emisión da Declaración de Incidencia Ambiental; cando se supere este prazo de dous meses a declaración entenderase favorable, quedando o promotor obrigado ao cumprimento de medidas preventivas, correctoras e de restauración que se propuxera orixinalmente na Memoria Ambiental.

Sen prexuízo das competencias atribuídas á Administración Autonómica, a Vixilancia e o control da Declaración de Incidencia Ambiental serán de competencia municipal. O incumprimento desta normativa será sancionada en aplicación da Lei 1/1995 de protección ambiental de Galicia.

No Anexo: Catálogo de actividades sometidas ao proceso de incidencia ambiental, este Anexo I recolle actuacións que xa recogía a Lei 21/ 2013 aínda que cun treito de diferenza, por exemplo a Lei 21/2013 de avaliación ambiental recolle que as instalacións de combustión para xeración de energía eléctrica con potencia térmica superior a $50 \mathrm{MW}$ deben ser sometidas a avaliación segundo a Lei 21/2013; o Anexo I indica que para aquelas instalacións de xeración eléctrica de potencia térmica entre 1 MW e 50 MW serán sometidas á Lei autonómica. É idéntico no caso doutras actividades industriais, agrícolas... nas que se rebaixa o limiar nacional a un treito inferior; ademais tamén se inclúen outras actuacións de menor entidade como poidan ser gasolineiras ou campos de golf.

\section{CONCLUSIÓNS}

A entrada en vigor da Lei 9/2013, do 19 de decembro, do emprendemento e da competitividade económica de Galicia e da Lei 21/2013, do 9 de decembro, de avaliación ambiental clarexan dalgunha maneira o procedemento de entrada en funcionamento dun novo establecemento despois da situación previa que provocara a derrogación do Regulamento de Actividades Molestas, Insalubres, Nocivas e Perigosas (R.A.M.I.N.P.) e en particular a aprobación da Lei 17/2009, do 23 de novembro, sobre o libre acceso ás actividades de servizos e o seu exercicio. Esta última (a Lei 17/2009) introducira a libre prestación de servizos e só permitía que estes estiveran condicionados a unha autorización previa en casos excepcionais aínda que ata ese momento era práctica normal 
que calquera nova actividade (servizos, comercial...) que se implantase en España tivera que esperar a obter a licenza de actividade que lle permitira inicíala.

A Lei 9/ 2013 clarexa a situación para a Comunidade Autónoma de Galicia, como norma xeral suprime a necesidade de licenza de actividade e substitúea por unha comunicación previa na que o titular declara o cumprimento de toda a normativa de aplicación. Unicamente nun grupo de limitadas excepcións a obtención da licenza esixe un documento ambiental previo emitido pola administración competente (neste caso o organismo ambiental da Comunidade Autónoma); así as actividades contaminantes podemos dividilas en tres grupos:

As que son grandes emisoras de gases contaminantes, recollidas na Lei 16/2002, do 1 de xullo, de Prevención e Control Integrados da Contaminación, que necesitan dispoñer da Autorización Ambiental Integrada

- As grandes contaminantes (emisións de gases, xeración de verteduras e residuos), reguladas pola Lei 21/2013, do 9 de decembro, de avaliación ambiental, que deben ser sometidas á Avaliación Ambiental Estratéxica ou Avaliación de Impacto Ambiental como procedementos de control; estes dous procedementos resólvense coa emisión da Declaración Ambiental Estratéxica ou a Declaración de Impacto Ambiental (ou os seus documentos resumidos en caso de se aplicar o procedemento simplificado). Nalgúns casos as actividades a realizar tamén se inclúen no ámbito de aplicación da Lei 16/2002, polo que 0 documento de control formará parte da Autorización Ambiental Integrada.

- $\quad$ As actividades contaminantes en menor medida, que están recollidas no propio Anexo da Lei 9/2013, e que precisan dispoñer da Declaración de Incidencia Ambiental. Nestes casos é necesario que ao se iniciar a actividade, o titular conte coa Declaración de Incidencia Ambiental positiva, así como que realice a correspondente comunicación ao concello; a non presentación destes documentos suporá que realiza a actividade sen cumprir a devandita autorización e polo tanto o inicio do procedemento sancionador.

\section{BIBLIOGRAFÍA}

[1] Constitución Española. Boletín Oficial del Estado núm. 311, de 29 de diciembre de 1978, páginas 29313 a 29424 (112 págs.)

[2] Ley Orgánica 1/ 1981, de 6 de abril, de Estatuto de Autonomía para Galicia. Boletín Oficial del Estado núm. 101, de 28 de abril de 1981, páginas 8997 a 9003

[3] Ley 7/1985, de 2 de abril, reguladora de las Bases del Régimen Local. Boletín Oficial del Estado núm. 80, de 3 de abril de 1985, páginas 8945 a 8964

[4] Decreto 2414/1961, de 30 de noviembre, por el que se aprueba el Reglamento de actividades molestas, insalubres, nocivas y peligrosas. Boletín Oficial del Estado núm. 292, de 7 de diciembre de 1961, páginas 17259 a 17271

[5] Ramón, F. L. NOTAS SOBRE ACTIVIDADES CLASIFICADAS (El régimen jurídico de la revisión y control de las licencias ambientales).

[6] Coria, I. D. (2008). El estudio de impacto ambiental: características y metodologías. Revista de la Universidad del Centro Educativo Latinoamericano, 11(020).

[7] Andrés, E. F. (2003). Actualidad sobre legislación medioambiental en España: políticas medioambientales de algunas empresas. Proyecto social: Revista de relaciones laborales, (10), 123-147. 
[8] Pernas García, J. J. (2013). La transposición de la directiva de emisiones industriales y su incidencia en la Ley 16/2002 de prevención y control integrados de la contaminación. Actualidad Jurídica Ambiental, (3), 1-54.

[9] Ley 82/ 1980, de 30 de diciembre, sobre conservación de energía, Boletín Oficial del Estado núm. 23, de 27 de enero de 1981, páginas 1863 a 1866

[10] Directiva del Consejo 85/337/ CEE, de 27 de junio de 1985, relativa a la evaluación de las repercusiones de determinados proyectos públicos y privados sobre el medio ambiente (DOCE núm. L 175 , de 5 de julio de 1985). http:// www.medioambientecantabria.es/documentos_contenidos/ 7060 1.1.pdf

[11] Rosa Moreno, J. (2004). La evaluación de impacto ambiental. Intervención de los entes locales.

[12] Real Decreto Legislativo 1302/ 1986, de 28 de junio, de evaluación de impacto ambiental. Boletín Oficial del Estado núm. 155, de 30 de junio de 1986, páginas 23733 a 23735

[13] Decreto 442/ 1990 de 13 de septiembre de Evaluación de Impacto Ambiental para Galicia. Diario Oficial de Galicia 25 septiembre 1990, núm. 188, [pág. 6275]

[14] Lei 1/ 1995, de 2 de xaneiro, de protección ambiental de la Comunidad Autónoma de

Galicia. Diario Oficial de Galicia núm. 29 de 10 de Febrero de 1995 y Boletín Oficial del Estado núm. 143 de 16 de Junio de 1995

[15] Larruga, F. J. S. (2000). Ley de protección ambiental de Galicia: sus bases jurídicas y principios ordenadores (y II). Revista xurídica galega, (29), 285-313.

[16] Álvarez, S. G. (2002). Medio ambiente. Revista galega de economía: Publicación Interdisciplinar da Facultade de Ciencias Económicas e Empresariais, 11(2), 349-354.

[17] Ley 16/2002, de 1 de julio, de Prevención y Control Integrados de la Contaminación. Boletín Oficial del Estado núm. 157, de 2 de julio de 2002, páginas 23910 a 2392

[18] Ministerio de Medioambiente, http:// www.magrama.gob.es/ es/ calidad-y-evaluacionambiental/ temas/ medio-ambiente-industrial/ prevencion-y-control-integrados-de-lacontaminacion-ippc/ autorizacion-ambiental-integrada-aai/

[19] Ley de Impacto Ambiental de proyectos, texto refundido aprobado por Real Decreto Legislativo 1/ 2008, de 11 de enero. Boletín Oficial del Estado núm. 23, de 26 de enero de 2008, páginas 4986 a 5000

[20] Ley 9/2006, de 28 de abril, sobre evaluación de los efectos de determinados planes y programas en el medio ambiente. Boletín Oficial del Estado núm. 102, de 29/ 04/ 2006

[21] Chaves, JR http:// contencioso.es/2010/ 04/ 07/ el-enredo-de-las-licencias-municipales-deactividad-ante-la-directiva-de-servicios

[22] Lei 9/2013, do 19 de decembro, do emprendemento e da competitividade económica de Galicia. Diario Oficial de Galicia, núm. 247 Viernes, 27 de diciembre de 2013 Pág. 50255

Revista Galega de Economía: http:/ / www.usc.es/ econo/ RGE/ benvidag.htm 
